\title{
Losing Control: Excessive Alcohol Seeking after Selective Inactivation of Cue-Responsive Neurons in the Infralimbic Cortex
}

\author{
Simone Pfarr, ${ }^{1 *}$ Marcus W. Meinhardt, ${ }^{1 *}$ Manuela L. Klee, ${ }^{1}$ Anita C. Hansson, ${ }^{1}$ Valentina Vengeliene, ${ }^{1}$ Kai Schönig, ${ }^{2}$

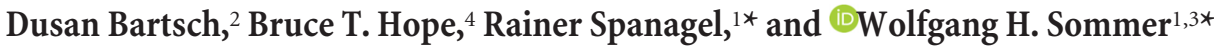 \\ ${ }^{1}$ Institute of Psychopharmacology, Departments of ${ }^{2}$ Molecular Biology and ${ }^{3}$ Addiction Medicine at Central Institute of Mental Health, Medical Faculty \\ Mannheim, University of Heidelberg, 68159 Germany, and ${ }^{4}$ IRP/ NIDA/ NIH, Behavioral Neuroscience Branch, Baltimore, Maryland 21224
}

Loss of control over drinking is a key deficit in alcoholism causally associated with malfunction of the medial prefrontal cortex (mPFC), but underlying molecular and cellular mechanisms remain unclear. Cue-induced reinstatement of alcohol seeking activates a subset of $\mathrm{mPFC}$ neurons in rats, identified by their common expression of the activity marker cFos and comprised of both principal and interneurons. Here, we used cFos-lacZ and pCAG-lacZ transgenic rats for activity-dependent or nonselective inactivation of neurons, respectively, which by their lacZ encoded $\beta$-galactosidase activity convert the inactive prodrug Daun02 into the neurotoxin daunorubicin. We report that activity-dependent ablation of a neuronal ensemble in the infralimbic but not the prelimbic subregion induced excessive alcohol seeking. The targeted neuronal ensemble was specific for the cue-induced response because stress-induced reinstatement was not affected in these animals. Importantly, nonselective inactivation of infralimbic neurons, using pCAG-lacZ rats, was without functional consequence on the cue-induced reinstatement task. Thus, inhibitory control over alcohol seeking is exerted by distinct functional ensembles within the infralimbic cortex rather than by a general inhibitory tone of this region on the behavioral output. This indicates a high level of functional compartmentation within the rat mPFC whereat many functional ensembles could coexist and interact within the same subregion.

Key words: alcohol self-administration; conditioned cues; Daun02 inactivation method; medial prefrontal cortex; neuronal ensembles; reinstatement

Significance Statement

Hebb's (1949) idea of memories as being represented in local neuronal networks is supported by identification of transiently stable activity patterns within subgroups of neurons. However, it is difficult to link individual networks to specific memory tasks, for example a learned behavior. By a novel approach of activity-dependent ablation, here we identify a specific neuronal ensemble located in the infralimbic subregion of the medial prefrontal cortex that controls a seeking response for alcohol in rats. Our data demonstrate that functional output depends on specific neuronal ensembles within a given brain region rather than on the global activity of that region, which raises important questions about the interpretation of numerous earlier experiments using sitedirected silencing or stimulation for elucidating brain function.

\section{Introduction}

Alcohol use accounts for a substantial proportion of global health burden (Whiteford et al., 2013). Whereas most alcohol users can

Received Feb. 16, 2015; revised May 26, 2015; accepted June 22, 2015.

Author contributions: M.W.M., R.S., and W.H.S. designed research; S.P., M.W.M., M.L.K., and V.V. performed research; K.S., D.B., and B.T.H. contributed unpublished reagents/analytic tools; S.P., M.W.M., A.C.H., and W.H.S. analyzed data; S.P., M.W.M., R.S., and W.H.S. wrote the paper.

This work was supported by Deutsche Forschungsgemeinschaft center grants (SFB636 subprojects B1 and D7 and SFB1134 subprojects B04 and B05) and by Bundesministerium für Bildung und Forschung within the frameworks of e:Med (BMBF 01ZX1311A) (Spanagel et al., 2013). We thank Jennifer Bossert and Nobuyoshi Suto for help with the cFos immunostaining protocol; and Elisabeth Röbel, Jana Zell, Sarah Meister, Sandra Dieter, Ina Broll, Esicka Domi, and Daniel Gehrlach for technical assistance. control their drinking behavior, others become excessive drinkers and may eventually develop an alcohol use disorder. Why control over alcohol consumption can break down in some individuals remains a fundamental question in addiction research.

Whether or not to engage in excessive alcohol drinking, is controlled by the medial prefrontal cortex (mPFC), which par-

The authors declare no competing financial interests.

*S.P., M.W.M., R.S., and W.H.S. contributed equally to this work.

Correspondence should be addressed to either Marcus W. Meinhardt or Wolfgang H. Sommer, CIMH, Square J5, 68159 Mannheim, Germany. E-mail: marcus.meinhardt@zi-mannheim.de, wolfgang.sommer@zi-mannheim.de. DOI:10.1523/JNEUROSCI.0684-15.2015

Copyright $\odot 2015$ the authors $\quad 0270-6474 / 15 / 3510750-12 \$ 15.00 / 0$ 
ticipates in executive brain functions both in primates and rodents (Heidbreder and Groenewegen, 2003; Wood and Grafman, 2003). Alcohol impairs mPFC functions both through its immediate pharmacological actions but more importantly long-term, whereby the underlying pathophysiological mechanisms are little understood. We recently demonstrated that the infralimbic cortex (IL), a subregion of the mPFC, exerts inhibitory control over alcohol seeking, and that this function shows long-term deficits in rats following a history of alcohol dependence (Meinhardt et al., 2013).

Alcohol seeking and taking are prototypical examples of associative learning whereby alcohol acts as a positive reinforcer and conditioned cues can drive further seeking responses (MartinFardon and Weiss, 2013). This form of learning is critically determined by local neuronal interactions (Buzsáki, 2010). An early theory of associative learning is Hebb's (1949) concept of memory representation in neuronal assemblies. Such networks are characterized by spatiotemporal patterns of neuronal activity, derived from defined sets of neurons (Wallace and Kerr, 2010). The next challenge is to demonstrate the functional involvement of distinct sets, here called "functional ensembles," in specific memory tasks. A distinct feature that has been associated with coherent neuronal activity is stimulus-induced $\mathrm{cFos}$ expression (Morgan and Curran, 1991). Although early studies linked cFos expression to neuronal activity (Sommer et al., 1993, 1996), only recently these neurons were directly implicated in internal representation and behavioral expression of distinct memories (Cruz et al., 2013, 2014a). Specific silencing of cFosexpressing neurons can be achieved in cFos-lac $Z$ transgenic animals whose $\beta$-galactosidase ( $\beta$-gal) activity converts the inactive prodrug Daun02 into daunorubicin, which disrupts functioning of c-Fos activated neurons (Farquhar et al., 2002; Cruz et al., 2013). According to these pharmacogenetic studies, behavioral control is exerted by a distinct subset of neurons, thereby challenging results from classical brain site-specific manipulations of neuronal activity. It has been proposed that the dorsomedial and ventromedial subdivisions of the mPFC, including the prelimbic (PL) and IL areas, exert opposing control over drug-seeking behaviors (Peters et al., 2008a,b, 2009). The demonstration of functional ensembles suggests a more complex view of behavioral control involving coexistence of many ensembles within one brain region supporting a variety of functions (Cruz et al., 2014a). However, although functional ensembles in a brain region can be identified by the Daun02 approach, it is difficult to distinguish the functional role of a local circuit inactivated by this method from that of the entire brain region. Global silencing requires classical lesion or pharmacological inactivation methods, making direct comparisons challenging.

Because alcohol-associated stimuli elicit cFos induction in the mPFC under reinstatement conditions (Wedzony et al., 2003; Zhao et al., 2006; Dayas et al., 2007; Willcocks and McNally, 2013; Marchant et al., 2014), we here test the hypothesis of functional ensembles and their involvement in alcohol seeking. For activitydependent Daun02 inactivation, we used cFos-lacZ (Kasof et al., 1995) transgenic rats that express the bacterial lac $Z$ gene under control of the activity-dependent cFos promoter. For nonselective Daun02 inactivation, we used pCAG-lacZ rats (Weber et al., 2011) ubiquitously expressing lacZ under the control of the pCAG promoter. We found that although alcoholassociated stimuli induce similar cFos responses in both IL and PL, only IL neurons form a functional ensemble that inhibits alcohol seeking.

\section{Materials and Methods}

Animals

Male cFos-lacZ transgenic rats (Kasof et al., 1995; 250-300 g, $n=40$ ), pCAG-lacZ rats (Weber et al., 2011; 250-300 g, $n=20$ ) both bred on a Sprague-Dawley genetic background in the breeding facility of the CIMH Mannheim, and wild-type littermate rats (250-300 g, $n=8)$ were housed in groups of four under a $12 \mathrm{~h}$ light/dark cycle with food and water available ad libitum in home cages. All behavioral testing was performed during the dark phase from 6:00 A.M. to 6:00 P.M., $5 \mathrm{~d}$ per week. All experiments were conducted in accordance with the EU guidelines for the care and use of laboratory animals and were approved by the local animal care committee (Regierungspraesidium Karlsruhe, Karlsruhe, Germany).

\section{Materials}

Ethanol and saccharin solution (Sigma-Aldrich; $10 \% \mathrm{v} / \mathrm{v}$ and $0.2 \% \mathrm{w} / \mathrm{v}$, respectively) were freshly prepared with tap water. Orange oil (Oleum Aurantii dulcis) was from Caelo. Daun02 was provided by NIDA and dissolved to final concentration of $4 \mu \mathrm{g} / \mu \mathrm{l}$ Daun 02 in 5\% DMSO and $5 \%$ Tween 80 in PBS ( $137 \mathrm{~mm} \mathrm{NaCl}, 2.7 \mathrm{~mm} \mathrm{KCl}, 8 \mathrm{~mm} \mathrm{Na} \mathrm{HPO}_{4}, 1.46 \mathrm{~mm}$ $\mathrm{KH}_{2} \mathrm{PO}_{4}, \mathrm{pH}$ 7.4). X-Gal (2315.4) was from C. Roth. Primary antibodies: monoclonal rabbit anti-cFos [c-Fos (9F6) mAb no. 2250, Cell Signaling Technology], monoclonal mouse anti-CaMKII (6G9 MA1-048, Pierce Biotechnology), monoclonal mouse anti-GAD67 and mouse antiNeuN-Cy3 (1G10.2 MAB5406 and clone A60, Cy3 conjugate, MAB377C3, Millipore), and chicken anti- $\beta$ galactosidase (ab9361, Abcam). Secondary antibodies: AlexaFluor 488-labeled donkey anti-rabbit and AlexaFluor 555-labeled donkey anti-mouse (A-21206 and A-31570, Invitrogen) and Cy3-labeled donkey anti-chicken (703-165-155, Jackson ImmunoResearch). N-benzyloxycarbonyl-Val-Ala-Asp-fluoromethyl ketone (Z-VAD-FMK), a pan caspase inhibitor, was obtained from Promega.

\section{General experimental design}

Four cohorts of animals were trained to self-administer a $10 \%$ alcohol solution (Experiment 1: $n=24$ cFos-lacZ rats; Experiment 2: $n=18$ pCAG-lacZ rats; Experiment 3: $n=16$ cFos-lacZ rats; Experiment 4: $n=$ 8 wild-type rats) in an operant cue-conditioning task followed by extinction (Sanchis-Segura and Spanagel, 2006). Guide cannulae were implanted (see next section) either aimed to target the IL (Experiments 1, 2, 4 ) or to the PL (Experiment 3) for subsequent Daun02 infusions after which the animals were allowed a $7 \mathrm{~d}$ recovery period, after which they underwent a cue-induced reinstatement session to activate a neuronal ensemble involved in this task (Fig. $1 A$, see time line). To inactivate the cue-responsive neurons, $90 \mathrm{~min}$ later rats received Daun02 or vehicle microinfusions via their implanted guide cannulas. Three days later rats were tested again for cue-induced reinstatement. Immediately after the second reinstatement test in Experiment 1, two animals per group were randomly removed and killed for $\mathrm{X}$-gal staining, to visualize lacZ activity. The remaining animals from Experiment 1 underwent additional cueinduced reinstatement sessions at 7 and $14 \mathrm{~d}$ post-Daun02 injection, without extinction sessions in between. These animals then underwent extinction training followed by a footshock stress-induced reinstatement. From all Experiments 3 cFos-lacZ rats and 4 pCAG-lacZ rats were excluded due to complications during the surgery procedure or because they failed to learn the operant tasks.

\section{Cannula guide implantation}

Rats were anesthetized with isoflurane. A single double-barreled cannula (22 gauge; Plastics One) was implanted on a Kopf stereotaxic frame using the following coordinates: AP: $+3.2 \mathrm{~mm}, \mathrm{ML}: \pm 0.5 \mathrm{~mm}$ for each cannula and DV: -2.8 relative to bregma (Paxinos and Watson, 1998). Obdurators were maintained throughout the experiments. Following surgery rats were single housed to prevent possible damage to the cannula. Behavioral testing was done after a $7 \mathrm{~d}$ recovery period.

\section{Microinfusions}

Double-barreled injector needles (28 gauge, Plastics One) were connected to polyethylene tubing, attached to a Hamilton syringe, fitted into an infusion pump. The injector needles extended $3 \mathrm{~mm}$ beyond the end 
A
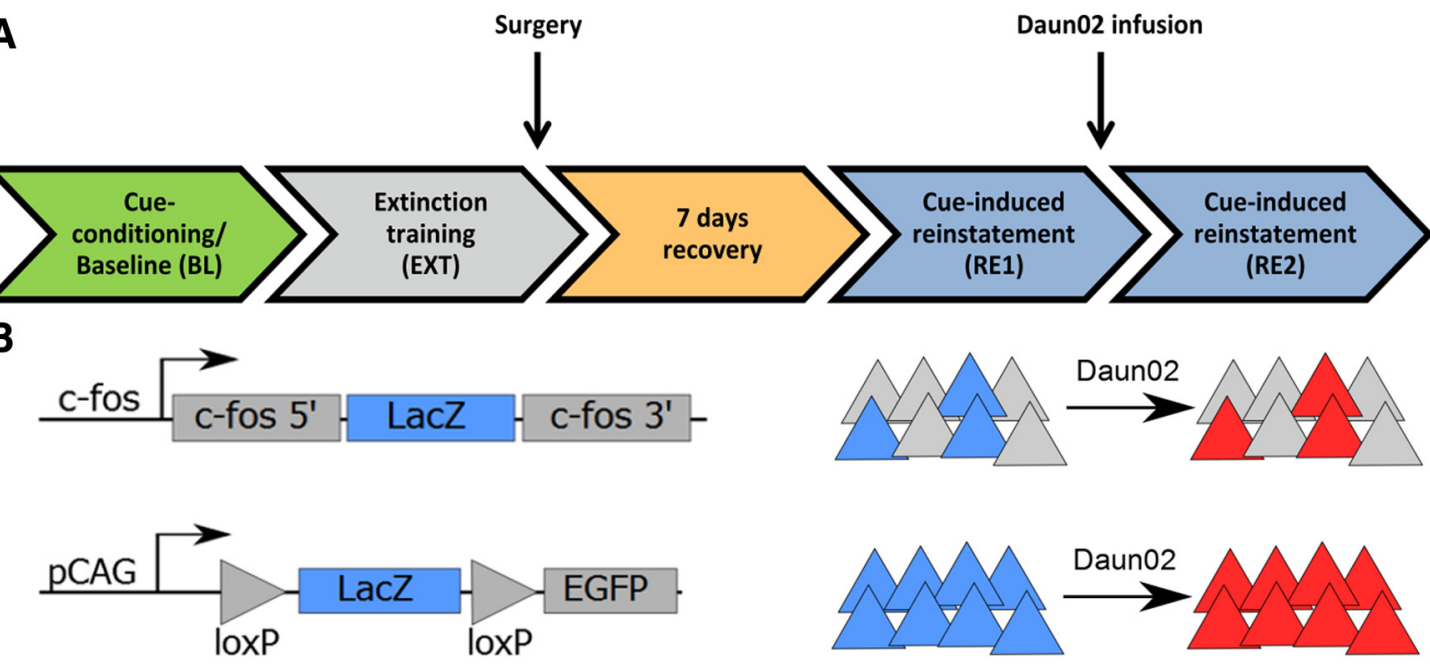

Figure 1. Experimental design and Daun02 inactivation method. $\boldsymbol{A}$, Time line of cue-induced alcohol self-administration, extinction, and repeated reinstatement (RE1, RE2) tests. $\boldsymbol{B}$, Principle designs of activity-dependent and nonselective neuronal inactivation by Daun02 in cFos-lacZ (top) and pCAG-lacZ (bottom) transgenic rats. Blue triangles represent lacZ-positive and activated cells, gray triangles represent nonactivated cells, and red triangles represent inactivated cells after Daun02 treatment.

of the cannula to target the IL and $1.2 \mathrm{~mm}$ beyond the end of the cannula to target the PL. One-half of the animals received bilateral Daun02 infusions, whereas the other half received bilateral vehicle infusions. Two micrograms Daun02 in $0.5 \mu$ l or the same volume of vehicle was infused over 2 min through each cannula (Koya et al., 2009). Injector needles were left in place for $1 \mathrm{~min}$ before rats were then returned to their home cages. Injection sites for each animal cohort are illustrated in Figure 5.

\section{Stereotaxic injections}

Three pCAG-lacZ rats were injected with $2 \mu \mathrm{g}$ Daun02 in the IL of one hemisphere and $2 \mu \mathrm{g}$ Daun02 $+80 \mathrm{ng} \mathrm{Z}$-VAD-FMK (solved in $1 \times \mathrm{PBS}$ containing $2 \%$ DMSO) in the other hemisphere. Three pCAG-lacZ rats were injected with Daun02 vehicle in the IL of one hemisphere and vehicle for both drugs in the other hemisphere. Rats were anesthetized, placed into a Kopf stereotaxic frame, and $1 \mu \mathrm{l}$ of the respective solutions was injected, using the coordinates: AP: $+3.2 \mathrm{~mm}, \mathrm{ML}: \pm 0.6 \mathrm{~mm}, \mathrm{DV}$ : -5.2 relative to bregma (Paxinos and Watson, 1998).

\section{Behavioral procedures}

Apparatus. All alcohol-seeking experiments were performed in operant chambers (MED Associates) enclosed in ventilated sound-attenuating cubicles. The chambers were equipped with a response lever on each side panel of the chamber. Responses at the appropriate lever activated a syringe pump that delivered a $\sim 30 \mu \mathrm{l}$ drop of fluid into a liquid receptacle next to it. A light stimulus (stimulus light) was placed above the right response lever of the self-administration chamber. An IBMcompatible computer controlled the delivery of fluids, presentation of stimuli, and data recording.

Operant alcohol self-administration. Alcohol self-administration training and testing sessions were performed $3 \mathrm{~h}$ after beginning of the dark phase, 5-6 d per week. Animals were trained to self-administer $10 \%(\mathrm{v} / \mathrm{v})$ ethanol in daily $30 \mathrm{~min}$ sessions on a fixed-ratio 1 schedule using a saccharin fading procedure modified from Tolliver et al. (1988). During the first $3 \mathrm{~d}$ of training, the animals were kept water deprived for $20 \mathrm{~h}$ per day. Responses at the left lever were reinforced by the delivery of $0.2 \%$ (w/v) saccharin solution. For the next $3 \mathrm{~d}$, animals underwent the same procedure without water deprivation. After successful acquisition of saccharin-reinforced responding, rats were trained to self-administer ethanol. During the next three sessions, responses at the left lever resulted in the delivery of $5 \%(\mathrm{v} / \mathrm{v})$ ethanol plus $0.2 \%$ saccharin solution. Responses at the right lever were recorded but had no programmed consequences. For the following sessions the concentration of ethanol was increased first to $8 \%$ and then to $10 \%(\mathrm{v} / \mathrm{v})$, and the concentration of saccharin was decreased until saccharin was completely eliminated from the ethanol solution.

Stimulus-conditioning phase. In the conditioning phase, the animals were trained to associate the availability of ethanol with the presence of specific discriminative stimuli. The stimulus-conditioning phase started immediately after completion of the saccharin-fading procedure. A combination of discriminative (olfactory) and contingent (visual) cues was used for conditioning, according to a well validated protocol published by Ciccocioppo et al., $(2002,2003)$ and Meinhardt et al. (2013). Two stimuli were used to predict the availability of $10 \%(\mathrm{v} / \mathrm{v})$ ethanol and were presented during each daily $30 \mathrm{~min}$ conditioning session. An orange odor served as an olfactory contextual stimulus for ethanol and was generated by application of six drops of orange extract onto the bedding material in the operant chamber before the start of each session. This stimulus was present throughout the whole session. In addition, a discrete visual stimulus was presented after correct responses resulting in ethanol delivery (left lever). As visual stimulus a $5 \mathrm{~s}$ blinking light was used, which was activated after a response at the active lever and was therefore directly connected to alcohol availability. The $5 \mathrm{~s}$ period served as a "time out", during which responses were recorded, but did not lead to reward delivery. For the stimulus-conditioning training, the animals had to complete 10 sessions with the two conditioned stimuli (CS). During the stimulus conditioning training responses at the right lever were recorded, but did not result in reward delivery (inactive lever). After the final stimulus-conditioning session, the animals were ranked based on their performance during the last six training sessions and equally distributed into two groups.

Extinction training. After successful completion of the stimulus conditioning phase all animals underwent daily 30 min extinction sessions for $4 \mathrm{~d}$ in a row, which was sufficient to reach an extinction criterion of $<10$ responses or $<25 \%$ of baseline activity at the active lever per session. During extinction sessions, both levers were extended without presentation of the olfactory CS (orange odor). Responses at the previously active lever activated the respective syringe pump, which however did not result in reward delivery or presentation of the discrete CS (blinking light). After the last extinction session, all animals underwent surgery.

Cue-induced reinstatement test. The animals were presented with the same conditioned stimuli (CS) as during the conditioning phase. Responses at the left (active) lever resulted in the presentation of the visual blinking light stimulus and activation of the syringe pump, which however did not result in reward delivery. Ninety minutes after the beginning of the first reinstatement session, the animals received their respective microinfusions (Daun02 or vehicle). Two animals from Experiment 1 
were killed and used for X-gal immunohistochemistry after the second cue-induced reinstatement session. The remaining animals from Experiment 1 were subjected to repeated cue-induced reinstatement sessions, a well established procedure for alcohol reinstatement tests (Ciccocioppo et al., 2006; Cannella et al., 2009). Between repeated cue-induced reinstatement sessions no extinction sessions were performed.

Stress-induced reinstatement of alcohol seeking. For the stress-induced reinstatement of alcohol seeking, a footshock protocol adapted from (Liu and Weiss, 2002) was used. Different operant chambers (Imetronic), which were environmentally distinct from those used for selfadministration (MED Associates) were used to stress the animals. After the last cue-induced reinstatement test, the animals underwent $5 \mathrm{~d}$ of extinction training in combination with habituation to the new operant chambers. For habituation, the animals were placed inside the new boxes for $10 \mathrm{~min}$ without cues or extended levers. After $10 \mathrm{~min}$ of habituation, the animals were moved into their normal self-administration chambers to undergo extinction training (as described above). On the day of stressinduced reinstatement, all animals were placed inside the new chambers and received variable intermittent footshocks for $10 \mathrm{~min}$. As settings for the footshock, we chose $0.5 \mathrm{~mA}, 0.5 \mathrm{~ms}$ duration, $40 \mathrm{~s}$ mean intershock interval with a range from 10 to $70 \mathrm{~s}$. The shock was delivered through a scrambler to the stainless steel grid floor of the footshock chambers. Directly after the $10 \mathrm{~min}$ footshock session, the animals were moved into the operant chambers (MED Associates), which were also used for the previous reinstatements. However, for the stress-induced reinstatement the same context as for extinction training was used, which means that only the levers are extended without the presentation of odor and light cues. Responses at the previously active lever resulted in the activation of the syringe pump without any reward delivery.

\section{Immunohistochemistry procedures}

Ninety minutes after the beginning of the last cue-induced reinstatement, at which cFos protein expression is at peak (Sheng and Greenberg, 1990), rats were deeply anesthetized with isoflurane and intracardially perfused with $100 \mathrm{ml}$ of $1 \times$ PBS followed by $200 \mathrm{ml}$ of fixative solution (phosphate buffer, containing 4\% paraformaldehyde and 14\% saturated picric acid). Brains were collected and postfixed for $24 \mathrm{~h}$ at $4^{\circ} \mathrm{C}$ in fixative solution. Postfixation for X-gal staining was for $1.5 \mathrm{~h}$ at room temperature.

For X-gal immunohistochemistry, $55 \mu \mathrm{m}$ coronal sections were cut using a vibrating blade microtome (Leica Microsystems). Brain sections were incubated in freshly prepared X-gal reagent $(0.6 \mathrm{mg} / \mathrm{ml}$ in $1 \times \mathrm{PBS}$ plus $5 \mathrm{~mm} \mathrm{~K}_{4} \mathrm{Fe}(\mathrm{CN})_{6}, 5 \mathrm{mM} \mathrm{K}_{3} \mathrm{Fe}(\mathrm{CN})_{6}$, and $\left.2 \mathrm{~mm} \mathrm{MgCl}_{2}\right)$ at $37^{\circ} \mathrm{C}$. The reaction was stopped by washing the sections with $1 \times \mathrm{PBS}$, brain sections were mounted on microscope slides using Immu-Mount (Fischer Scientific) and were investigated using a stereo microscope (Carl Zeiss). For quantification, the number of positively stained nuclei was determined by applying the cell-counter analysis macro of ImageJ covering an area of $1 \mathrm{~mm}^{2}$ within the IL.

For fluorescent double-labeling immunohistochemistry $40-\mu \mathrm{m}$-thick coronal sections were cut, collected in $1 \times$ PBS, washed three times in $1 \times$ TBS and then incubated in blocking solution (7.5\% donkey serum, $2.5 \%$ BSA in $1 \times$ TBS with $0.2 \%$ Triton $\mathrm{X}-100$ ) for $1 \mathrm{~h}$. For cFos/NeuN doublelabeling sections were incubated with the anti-cFos antibody (rabbit, 1:500) and the anti-NeuN-Cy3-conjugated primary antibody (mouse, 1:500) in blocking solution for $24 \mathrm{~h}$ at $4^{\circ} \mathrm{C}$. The sections were then washed three times in $1 \times \mathrm{TBS}$ and incubated for $1 \mathrm{~h}$ in $1 \times \mathrm{TBS}$ with $0.2 \%$ Triton X-100 (TBS-Tx) containing the secondary antibody AlexaFluor 488-labeled donkey anti-rabbit (1:200 dilution). For cFos/CaMKII and Fos/GAD67 double-labeling sections were incubated for $24 \mathrm{~h}$ at $4^{\circ} \mathrm{C}$ with the anti-cFos antibody (rabbit, 1:500 dilution) and either anti-CaMKII (mouse, 1:500) or anti-GAD67 (mouse, 1:1000) antibody in blocking solution, then washed three times in $1 \times$ TBS and incubated for $1 \mathrm{~h}$ in TBS-Tx containing a mixture of secondary antibodies (AlexaFluor 488labeled donkey anti-rabbit, 1:200, and AlexaFluor 555-labeled donkey anti-mouse, 1:200). For cFos/ $\beta$-gal double-labeling anti-cFos antibody (rabbit, 1:500) and anti- $\beta$-gal antibody (chicken, 1:10,000) in blocking solution were used. Secondary antibody solution contained AlexaFluor 488-labeled donkey anti-rabbit (1:200) and Cy3-labeled donkey anti- chicken (1:1000). Following staining all sections were washed three times in $1 \times$ TBS and mounted as described above.

Slides were investigated using a Leica TCS SP2 imaging system mounted on a DM IRE2 microscope (Leica Microsystems) using an $63 \times$ oil-planchromat lens with an NA 1.3 and either an argon ion laser (458$514 \mathrm{~nm}$ ) or a green neon laser $(543 \mathrm{~nm})$. Z-stacks were acquired with sections taken every $0.99 \mu \mathrm{m}$. All images were saved as Tiff files. For quantification, three Z-stacks were acquired per hemisphere from infralimbic or prelimbic region of eight rats. The number of all NeuN stained cells and the number of cFos and NeuN colocalized cells was counted using the cell counter analysis macro of ImageJ. The percentage of colocalization was calculated for each animal and the mean \pm SEM for the eight animals was calculated. For quantification of cFos + GAD67 or CaMKII colocalization, the number of all cFos stained cells and the number of the cFos and GAD67 or CaMKII colocalized cells was counted and the percentage of colocalization was determined as described above.

For Fluorojade B staining rats were perfused as described above and the brains were postfixed in the fixative for $24 \mathrm{~h}$ at $4^{\circ} \mathrm{C}$, dehydrated in $1 \times$ $\mathrm{PBS} / 10 \%$ sucrose solution for $3 \mathrm{~d}$ and flash frozen at $-80^{\circ} \mathrm{C}$. A standard Fluorojade B staining protocol was used (Schmued and Hopkins, 2000) and the slides were cleared by immersion in xylene for $1 \mathrm{~min}$ and coverslipped with Eukitt quick-hardening mounting medium (SigmaAldrich). Overview images of Fluorojade B-labeled sections were acquired using a Zeiss Axioskop 2 plus microscope with a $2.5 \times$ lens. Image analysis was performed using ImageJ. First, the images were transformed into an 8-bit gray scale image. Then a region-of-interest (ROI) was defined for the MPFC in each image, followed by the measurement of the integrated density of each ROI.

\section{Statistics}

Data are expressed as mean \pm SEM. Behavioral data were analyzed using two-way ANOVA with repeated measures, followed by Newman-Keuls post hoc tests, where appropriate, using the program Statistica 10 (StatSoft). Alpha level for significant effects was set to 0.05 . The dependent measures and the factors used in the statistical analyses are described in Results. The X-gal staining was analyzed by two-tailed $t$ test. Fluorojade-B data were analyzed by one-way ANOVA.

\section{Results \\ Daun02 permanently inactivates $\boldsymbol{\beta}$-gal-expressing neurons by neurodegeneration}

In cFos-lac $Z$ rats the lac $Z$ transgene encoding the enzyme $\beta$-gal is coexpressed with the gene expression-dependent neural activity marker cFos. $\beta$-gal enzyme converts the inactive prodrug Daun02 into the active compound daunorubicin, thereby disabling lacZ-expressing neurons. Thus, by controlling $\beta$-gal expression by the cFos promotor it is possible to specifically inactivate those neurons that are engaged in a distinct task involving cFos induction (Koya et al., 2009; Fig. 1B). We first establish that cue-induced reinstatement of alcohol seeking, a widely used animal model of relapse (Crombag and Shaham, 2002; Epstein et al., 2006; Sanchis-Segura and Spanagel, 2006; Martin-Fardon and Weiss, 2013; Marchant et al., 2014), induces colocalization of cFos and $\beta$-gal in neurons of the medial prefrontal cortex (Fig. $2 A)$. Daun02 microinjections into the IL after this session cause a significant decrease of $\beta$-gal-positive cells in this region by the second reinstatement compared with the vehicle injected group $(t=5.23, p<0.01$; Fig. $2 B)$, thus demonstrating the specific inactivation of neurons engaged in the cue-induced reinstatement task.

We also introduce a new tool for nonselective inactivation using Daun02. The transgenic pCAG-lacZ rat line expresses $\beta$-gal constitutively under the pCAG promoter (Weber et al., 2011; Schönig et al., 2012), thus Daun02 treatment will affect the entire injected area (Fig. 1B). Using this line, it has now become possible to compare the effects of task-specific versus nonspecific inacti- 
A

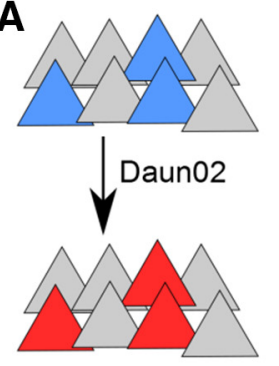

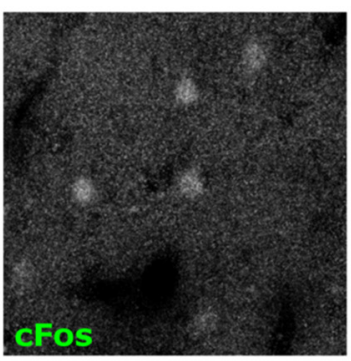

B

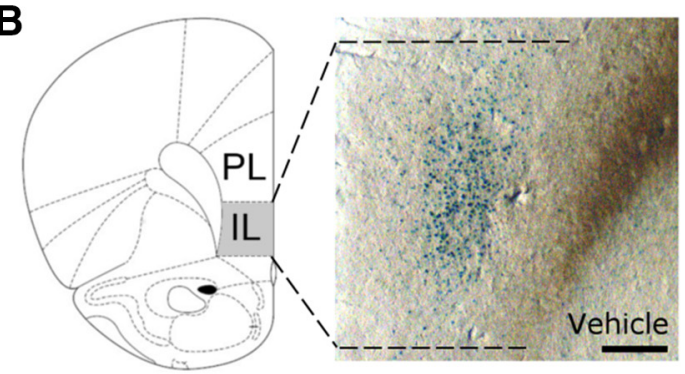

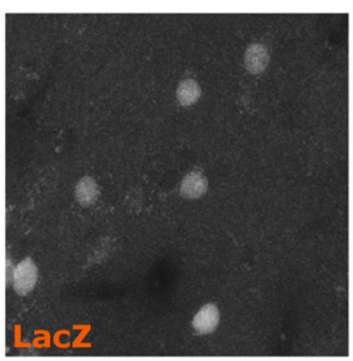
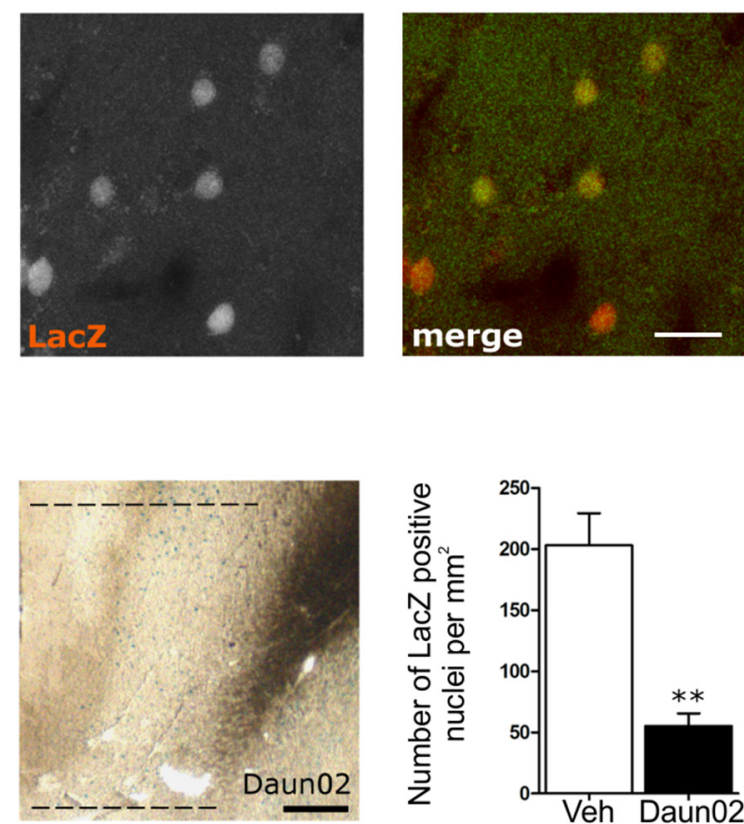

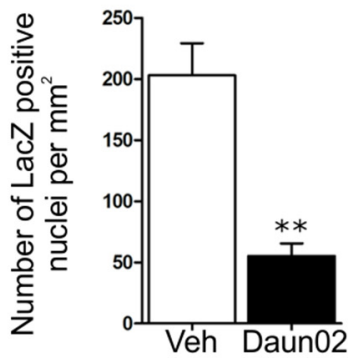

Figure 2. Activity-dependent Daun02 inactivation in cFos-lacZ rats. A, Exposure to alcohol-associated cues results in coexpression of cFos and lacZ in cFos-lacZ rats. Scale bar, $20 \mu$ m. $\boldsymbol{B}$, Representative X-Gal staining of lacZ-positive cells in the IL region of (Fos-lacZ rats after RE2. Scale bar, $300 \mu \mathrm{m}$. Drawing of coronal section adapted from Paxinos and Watson (1998). Quantification of lacZ-positive nuclei after RE2 showed a significant reduction in CFos-lacZ rats after Daun02 treatment compared with vehicle. ${ }^{* *} p<0.01$.

vation within distinct brain regions using the same method, i.e., Daun02 inactivation. Because of the global $\beta$-gal expression, this line is also well suited to study the mode of action of Daun02 on neurons. Two concurring hypothesis regarding daunorubicin's mechanism of action in neurons have been put forward: temporary silencing by inhibition of calcium channels leading to reduced excitability (Santone et al., 1986; Engeln et al., 2014) or alternatively, permanent inactivation by neuronal death via apoptosis (Mortensen et al., 1992; Jantas and Lason, 2009). To test the latter hypothesis, we injected $2 \mu \mathrm{g}$ Daun02 or $2 \mu \mathrm{g}$ Daun02 + $80 \mathrm{ng} \mathrm{Z}$-VAD-FMK, or vehicle alone into the mPFC of pCAG-lacZ rats. $Z$-VAD-FMK is a pan-caspase inhibitor with anti-apoptotic properties (Hara et al., 1997). Three days after the stereotaxic injection, rats were killed and brain sections stained with Fluorojade-B to detect degenerated neurons (Schmued and Hopkins, 2000). We found massive neurodegeneration after Daun02 injection, that was largely prevented by Z-VAD-FMK $\left(F_{(1,18)}=\right.$ 54.8, $p<0.001$; Fig. $3 A$ ). According to these results, inactivation of $\beta$-gal-expressing neurons by Daun02 involves apoptotic mechanisms. Consequently, effects on neuronal function are likely to be permanent.

To validate the specificity of the Daun02 inactivation we compared the results of Fluorojade-B staining in pCAG-LacZ and cFos-LacZ rats. As described above, c-Fos-LacZ rats were tested on cue-induced reinstatement of alcohol seeking followed by injection of Daun02 via previously implanted cannulae and killed 3 dater. As shown in Fig. $3 B$, the whole injected brain area shows fluorescent signal, demonstrating massive cell damage in the pCAG-LacZ rats after Daun02 infusions. By contrast, under activity-dependent conditions in cFos-LacZ rats using the same amount of Daun02 we found a scattered pattern of fluorescence signal, which is consistent with the amount of cFos-positive cells observed in the region, demonstrating the specificity of the Daun02 method. There was no visible fluorescent signal after vehicle injections in the cFos-LacZ line.

\section{Cue-activated neuronal ensembles within the IL exert inhibitory control over alcohol seeking}

Using cFos-lacZ and pCAG-lacZ transgenic rats allowing task specific or nonspecific global inactivation of neurons by Daun02, respectively, we first investigated the role of neuronal ensembles in the IL for cue-induced alcohol-seeking behavior. After acquisition of cue conditioned alcohol self-administration, the two cohorts of rats were ranked based on their response rates over the last six sessions (baseline) and assigned into separate prospective Daun02 and control groups (cFos-lacZ: $n=10$ vs11, $F_{(1,19)}=$ 1.214, n.s.; pCAG-lacZ: $n=7$ /group, $F_{(1,11)}=0.618$, n.s.; for responses at the inactive lever and injection sites for all experiments see Fig. 5). Next, all rats underwent extinction training resulting in $<10$ responses at the active lever, were then implanted with guide cannulas to target the IL, and tested after 1 week of recovery for cue-induced reinstatement (RE1), which served to activate cue-responsive neurons. All cFos-lacZ and pCAG-lacZ animals showed a significant increase in responding between the last extinction session and cue-induced reinstatement of alcohol seeking (two-way repeated-measures ANOVA; cFos-lacZ rats: main effect of sessions, $F_{(1,19)}=14.8, p=0.001$; of prospective group assignment, $F_{(1,19)}=0.1$, n.s., and interaction, $F_{(1,19)}=0.04$, n.s.; Newman-Keul's post hoc test extinction vs RE1 $p<0.001$ for both groups; pCAG-lacZ rats: session, $F_{(1,11)}=$ 55.3, $p<0.001$; group, $F_{(1,11)}=0.3$, n.s., and interaction, $F_{(1,11)}=$ 0.06 , n.s.; post hoc test for both groups $p<0.05$; Figs. $4 A, B$, $5 A, B)$. Ninety minutes after the beginning of the reinstatement session, all animals received their respective control or Daun02 microinjections (Fig. 5 shows cannula placements). The animals were then returned to their home cages for $3 \mathrm{~d}$ before being tested on a second cue-induced reinstatement (RE2). Selective inactivation of IL cue-responsive neurons by Daun02 in cFos-lacZ rats as demonstrated by $\beta$-gal staining (Fig. $2 B$ ) caused a significant increase in alcohol-seeking responses in the Daun02 group, but not in the control group (Fig. 4A, Fig. 5A). Two-way repeated- 
A

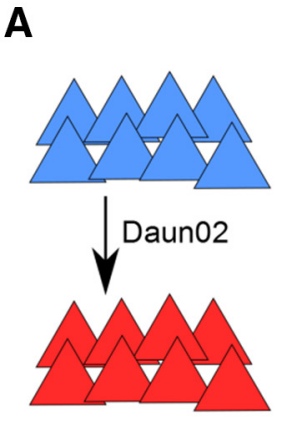

Daun02 +

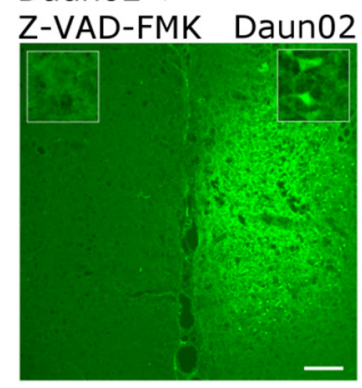

B

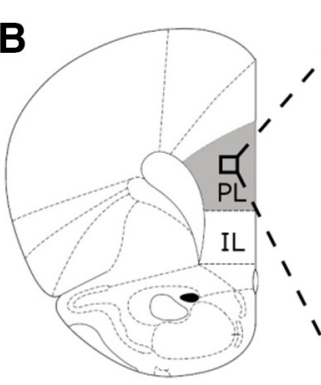

CAG-LacZ

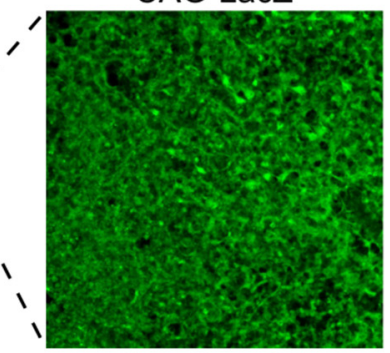

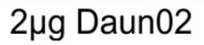
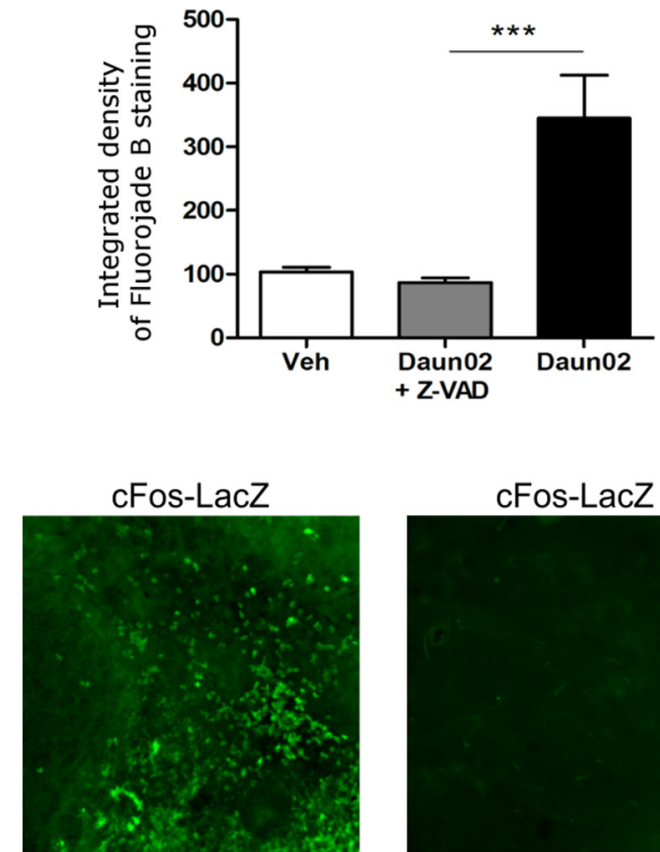

$2 \mu \mathrm{g}$ Daun02

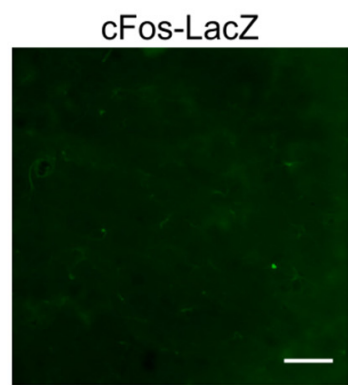

vehicle

Figure 3. Characterization of Daun02 inactivation in pCAG-lacZ rats. $A$, Representative image of Daun02 and Daun02 + Z-VAD-FMK injections into the mPFC of pCAG-lacZ rats. Scale bar, $300 \mu \mu m$. Fluorojade-B signal is visible by green fluorescence. Daun02 injections induced a high level of neurodegeneration, whereas there was less Fluorojade-B signal in the Daun02 + Z-VAD-FMK injection site. Integrated density measurement of Fluorojade-B signal in $\mathrm{mPFC}$ (mean $\pm \mathrm{SEM}, n=30$ sections/group). The combination of Daun02 $+Z$-VAD-FMK significantly reduced the Fluorojade-B signal. ${ }^{* * *} p<0.001$. For detailed statistics, see Results. $\boldsymbol{B}$, Representative images of Flurojade-B stainings are shown for cFos-LacZ rats after cue-induced reinstatement and for pCAG-LacZ rats. 2 $\mu \mathrm{g}$ Daun02 injections into the PL of pCAG-LacZ rats induced massive neurodegeneration. Daun02 infusions into cFos-lacZ rats after cue-induced reinstatement caused less, therefore specific neurodegeneration. Vehicle injections into cFos-lacZ rats caused no neurodegeneration. Scale bar, $25 \mu \mathrm{m}$.

measures ANOVA confirmed a significant main effect of the sessions $\left(F_{(1,19)}=18.2, p<0.001\right)$ and a significant interaction $\left(F_{(1,19)}=10.05, p<0.01\right)$, but no significant effect of treatment $\left(F_{(1,19)}=3.71, p=0.069\right)$. The post hoc test revealed a significant difference between RE1 versus RE2 for the Daun02 group ( $p<$ 0.001 ) but not for the control group ( $p>0.05$; Figs. $4 A, 5 A$ ). This experiment indicates that a distinct group of IL neurons forms neuronal ensembles that are involved in retrieval of the alcohol memory and in inhibiting the associated response, i.e., lever pressing for obtaining the alcohol reward. Interestingly, nonselective inactivation of IL neurons in pCAG-lacZ rats had no significant consequences on alcohol-seeking behavior (two-way repeated-measures ANOVA: effect of session, $F_{(1,1)}=2.2$, n.s.; treatment, $F_{(1,11)}=0.003$, n.s.; and interaction, $F_{(1,11)}=0.272$, n.s.; Figs. $4 B, 5 B)$. Thus, only task-selective inactivation of cueresponsive neurons leads to increased alcohol seeking upon cue presentation, whereas a nonspecific lesion did not result in a measurable effect. Consequently, the resulting deficits from a global lesion of the IL can either be rapidly compensated by other brain regions or opposing processes within the IL are engaged in controlling alcohol seeking resulting in a zero net effect.

\footnotetext{
The selective Daun02 inactivation of cue-responsive neurons is persistent

Previous studies followed the effects of Daun02 inactivation only up to 3 d (Koya et al., 2009; Bossert et al., 2011). Given our finding that Daun02 causes permanent inactivation of task-activated neurons, we hypothesized that the behavioral consequences should be long lasting. We therefore subjected the cFos-lacZ rats from Experiment 1 to two additional cue-induced reinstatement
}

tests (RE3 and RE4, days 7 and 14 post-Daun02 infusion). As expected, we found no differences in alcohol-seeking behavior between sessions RE2 and RE4 (two-way repeated-measures ANOVA: effect of treatment, $F_{(1,15)}=5.41, p<0.05$; session, $F_{(2,30)}=0.01$, n.s.; and interaction, $F_{(2,30)}=0.29$, n.s.; Figs. $4 C$, $5 C)$. Thus, the behavioral effects of Daun02 lesions last at least for 2 weeks and are most likely even longer lasting because all activated neurons undergo apoptosis.

\section{Neural circuits of cue- or stress-induced alcohol seeking differ in the IL}

In addition to presentation of alcohol cues, a reinstatement of alcohol seeking is also reliable elicited by stress (Martin-Fardon and Weiss, 2013). Because the IL integrates information from various brain regions including those processing emotional states, we wanted to test whether the cue-activated neuronal ensemble lesioned by Daun02 could also be involved in the processing of stress-induced reinstatement. The cFos-lacZ animals from above were exposed to $10 \mathrm{~min}$ of intermittent footshocks before the beginning of the reinstatement session that was conducted in the same context as for extinction, i.e., without presentation of specific alcohol-associated cues. The baseline responses from the previous experiment were $30.8 \pm 6.2$ for the control and $32.5 \pm$ 4.9 for the Daun02 group. Both the control and the Daun02 group significantly increased their active lever responses in the stress-induced reinstatement compared with their extinction performance, however, there was no significant difference between the groups (two-way repeated-measures ANOVA: main effect of the sessions, $F_{(1,11)}=31.57, p<0.001$; treatment, $F_{(1,11)}$ $=0.51$, n.s.; and interaction, $F_{(1,11)}=0.33$, n.s.; Newman-Keul's post hoc test: $p<0.05$ extinction vs reinstatement session for both 
A

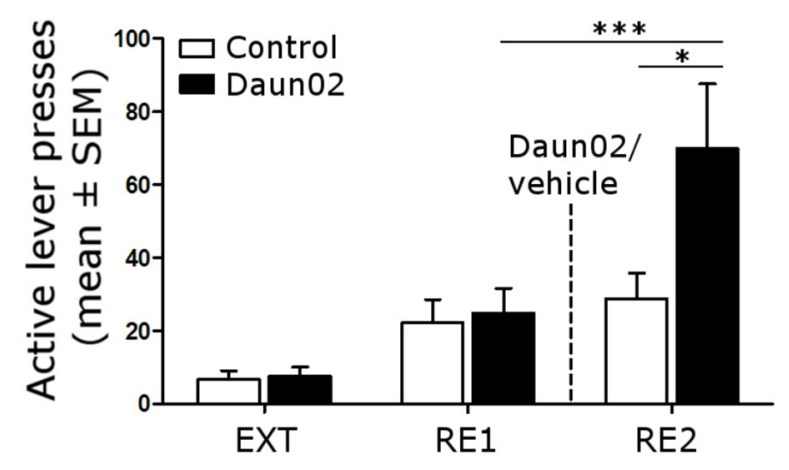

C
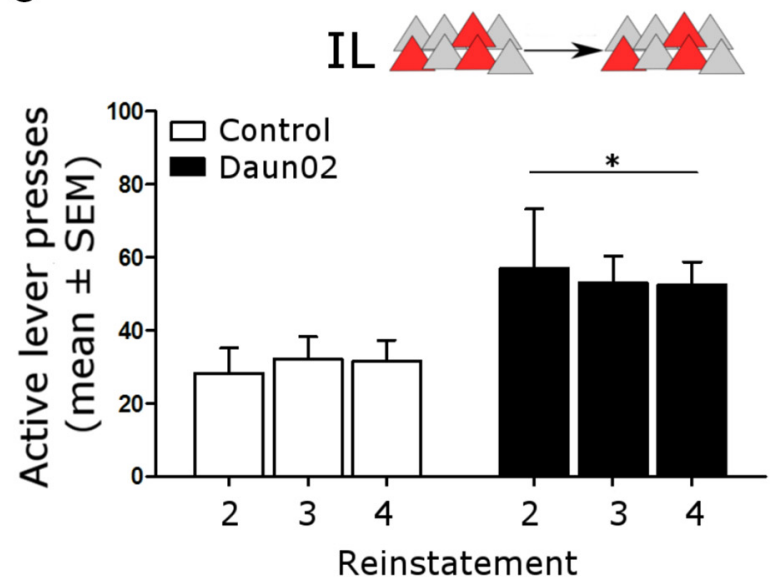

$\mathbf{E}$

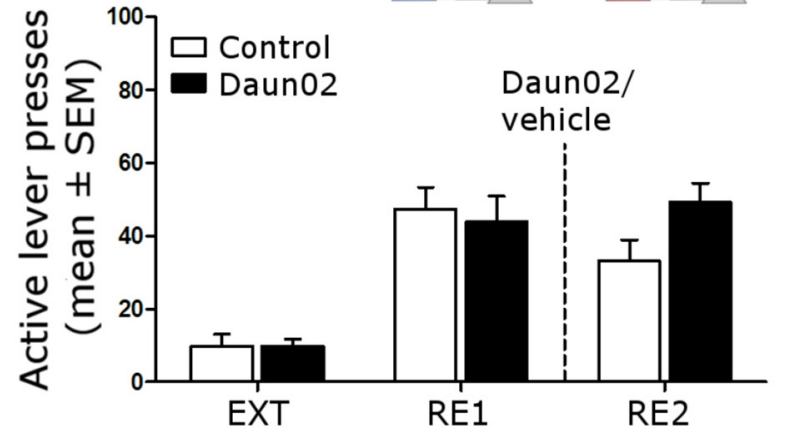

B
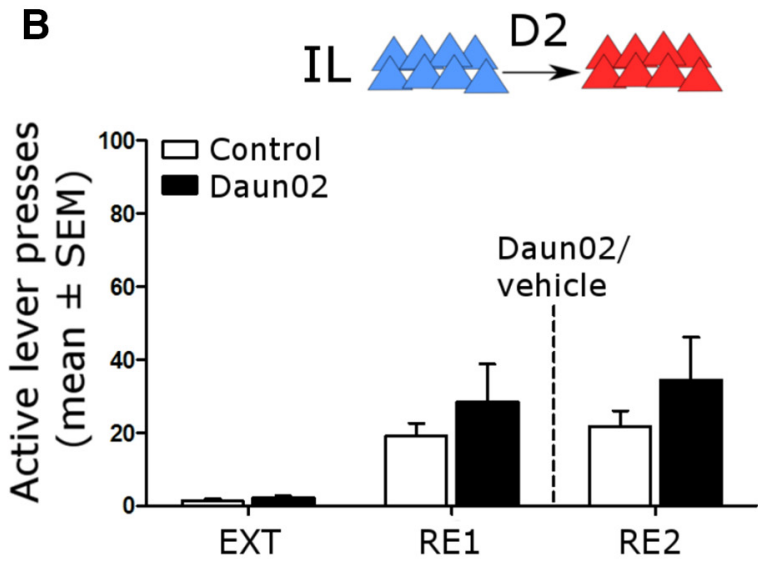

D
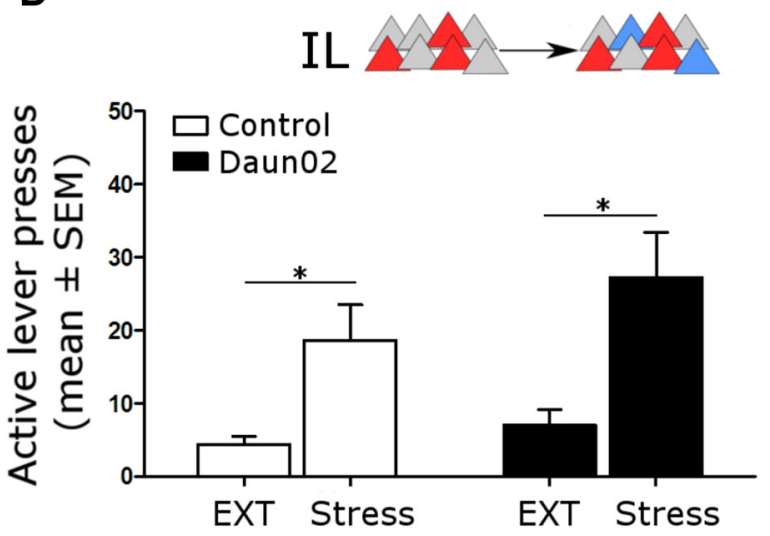

$\mathbf{F}$

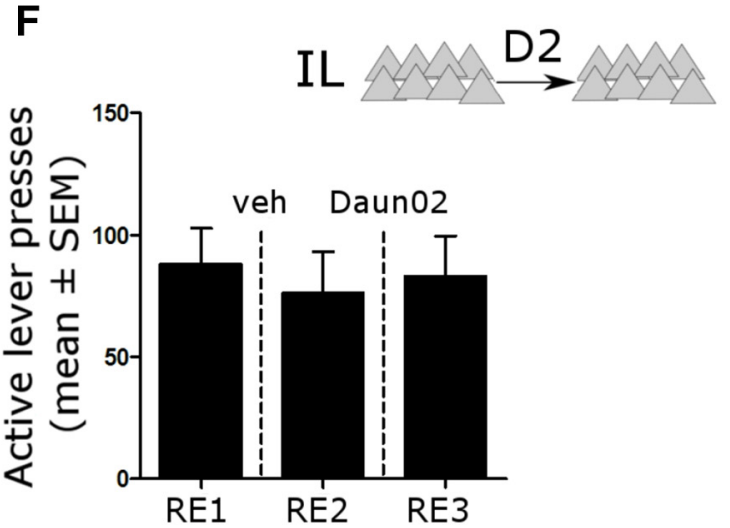

Figure 4. Effects of mPFC Daun02 inactivation on alcohol-seeking behavior. Responses at the active lever (mean + SEM) are shown during extinction (EXT) and reinstatement before (RE1) and after (RE2) Daun02 injection. Principle schemes as in Figure 1B. D2, Daun02.A, Daun02 microinjection into IL of cFos-lacZ rats after RE1 resulted in a significant increase in alcohol seeking in RE2 ( $n=$ $10-11 /$ group). $\boldsymbol{B}$, Nonselective IL inactivation by Daun02 in PCAG-lacZ rats ( $n=7 /$ group) was without effect on reinstatement behavior. $\boldsymbol{C}$, The increase in alcohol seeking in the $c$ Fos-lacZ rats from $A$ after Daun02 treatment persists for at least 2 weeks (RE2 same as in $A$ ), RE3 at 7, and RE4 at $14 \mathrm{~d}$ after RE1 ( $n=8-9$ /group). Red triangles represent cells inactivated in $A$. D, The cFos-lacZ animals from $\boldsymbol{A}$ were tested on stress-induced reinstatement of alcohol seeking. There was no significant difference between the groups $(n=6-8 /$ group). Red triangles represent cells inactivated in $\boldsymbol{A}$. Blue triangles represent newly activated cells by stress. $\boldsymbol{E}$, Daun02 microinjection into PL of cFos-lacZ rats after RE1 has no effect on alcohol-seeking behavior. $\boldsymbol{F}$, Microinjections of vehicle and Daun02 into IL of wild-type littermates had no effect on cue-induced reinstatement. Gray triangles represent lacz-negative cells. ${ }^{*} p<0.05 ;{ }^{* *} p<0.01{ }^{* * * *} p<0.001$. For detailed statistics, see Results.

groups; Figs. 4D, 5D). Thus, despite highly similar behavioral outputs, i.e., lever pressing for alcohol, the response to stress involves different sets of neurons than the ones processing specific alcohol associated cues.
The majority of cue-responsive neurons are glutamatergic

To further characterize the cue responsive neurons in the mPFC, eight cFos-lacZ rats were killed 90 min after a reinstatement session and brain sections were double-stained for $\mathrm{cFos}$ and cell- 


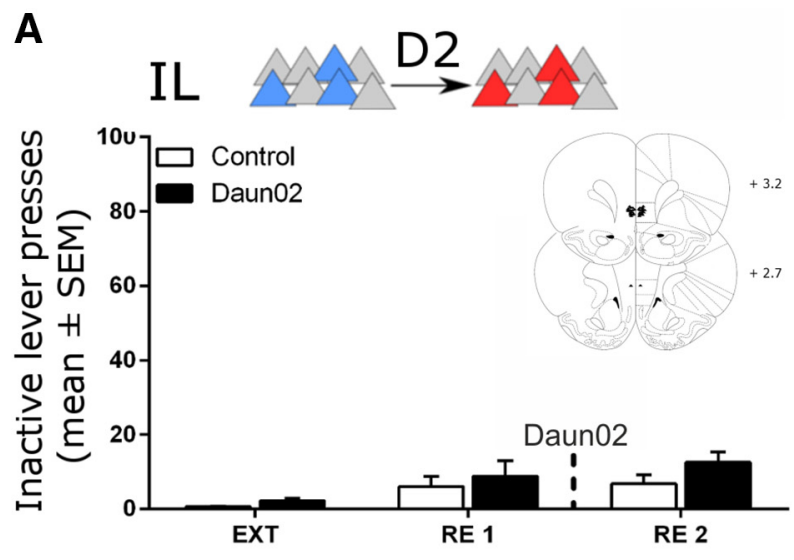

B

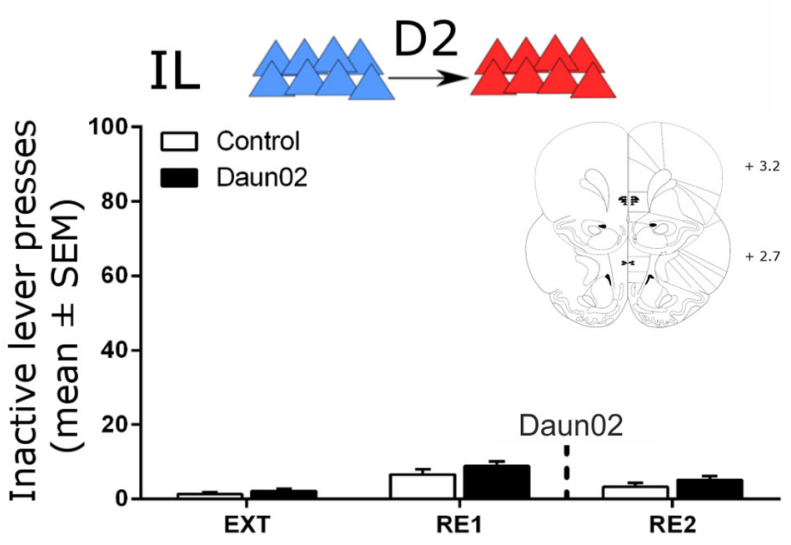

C
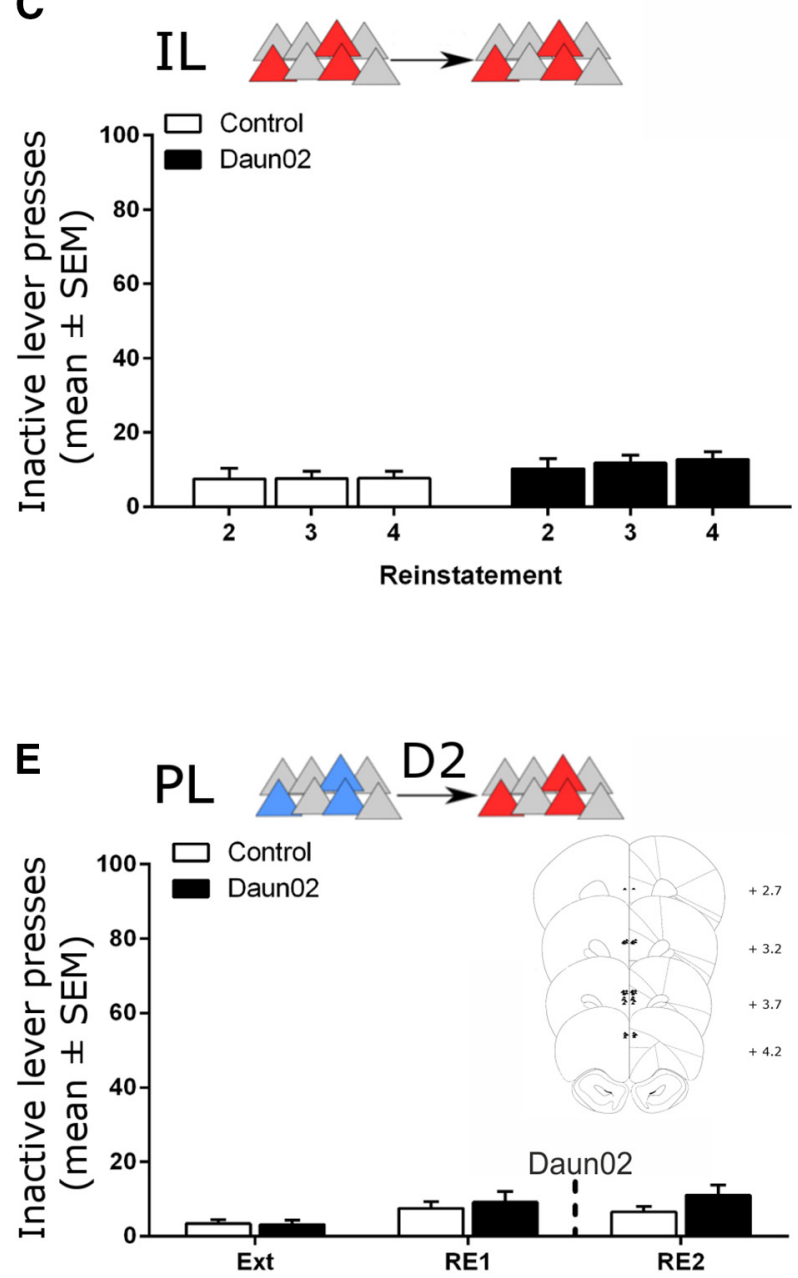

D

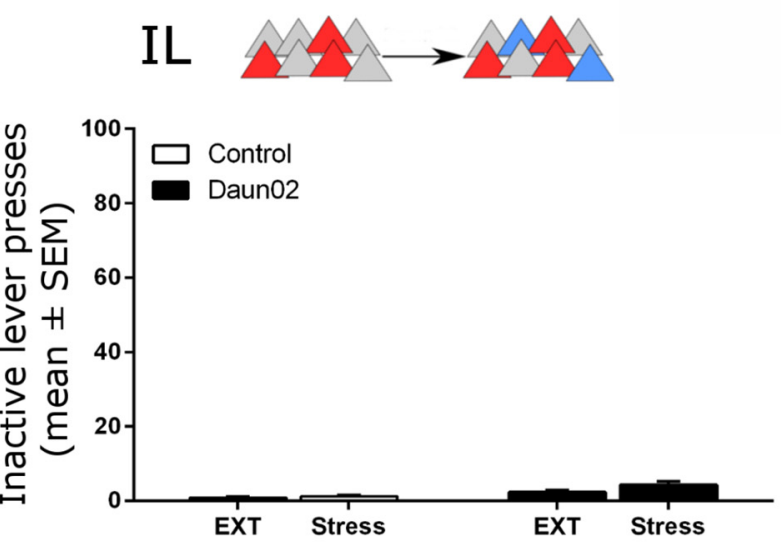

$\mathbf{F}$
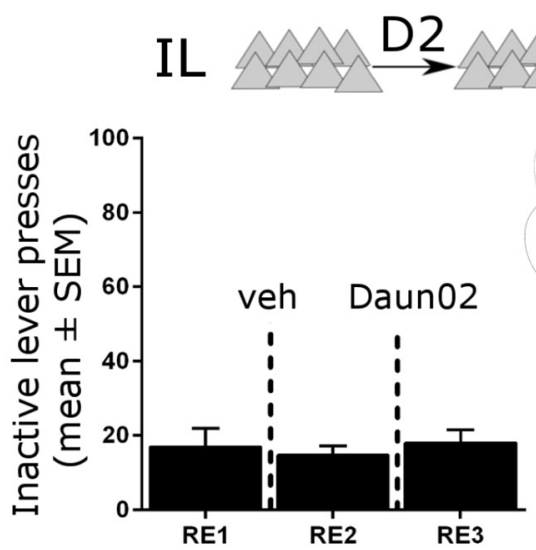

Figure 5. Inactive lever responses from Daun02 inactivation experiments and cannula placements. For explanation of triangles see Figures $2-4 . A$, Responses at the inactive lever (mean \pm SEM) during extinction (EXT) and reinstatement before (RE1) and after (RE2) Daun02 injection into IL of cFos-LacZ rats. There were no significant differences between the groups during EXT, RE1, and RE2 ( $n=10-11 /$ group). $\boldsymbol{B}$, There was also no significant difference in inactive lever presses after nonselective IL inactivation by Daun02 in pCAG-LacZ rats $(n=7 / \mathrm{group})$. C , The animals from $\boldsymbol{A}$ were further tested on their reinstatement behavior. There was again no significant difference in inactive lever presses between the groups ( $n=8-9 / \mathrm{group})$. D, The cFos-LacZ animals from $\boldsymbol{A}$ and $\boldsymbol{C}$ were tested on a stress-induced reinstatement of alcohol-seeking task. There was no significant difference in inactive lever presses between the groups $(n=6-8 /$ group). $\boldsymbol{E}$, There was no significant difference in inactive lever presses between the groups in a third cohort of animals, which received PL Daun02 injections. $F$, There was no significant difference in inactive lever presses in cue-induced reinstatements of wild-type animals after IL vehicle and Daun02 injections. Approximate locations of the 28 gauge injection-cannula tips are indicated by small black triangles. Cannula placements were verified within the infralimbic cortex from +3.2 to +2.7 anterior to bregma and within the prelimbic cortex from +4.2 to +2.7 anterior to bregma (Paxinos and Watson, 1998 ). 
A
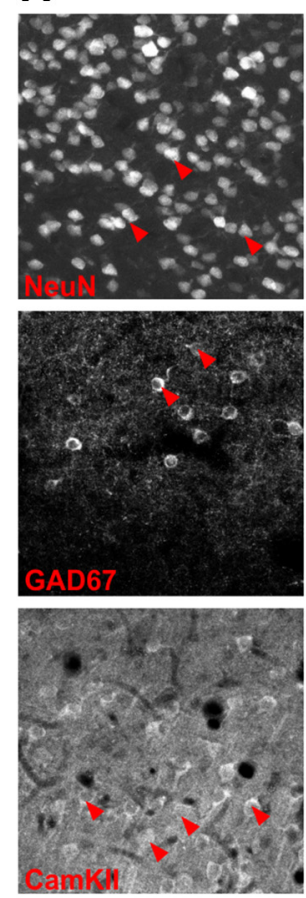
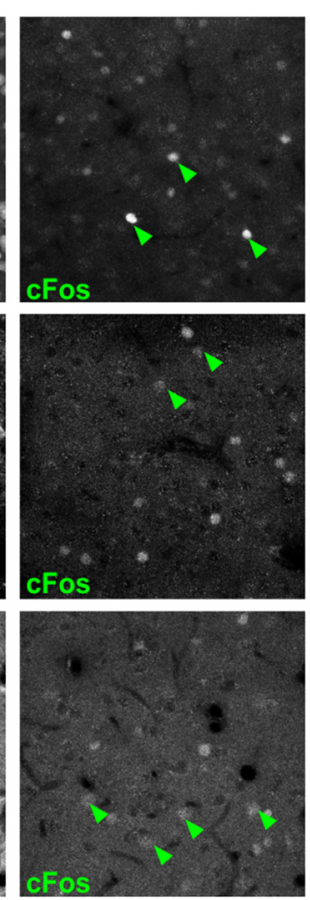
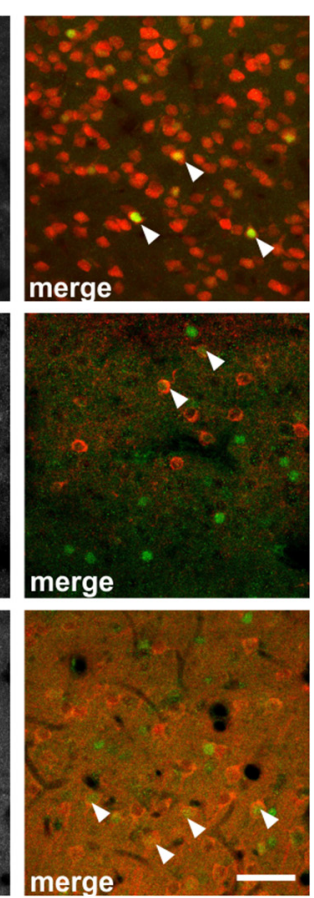

B
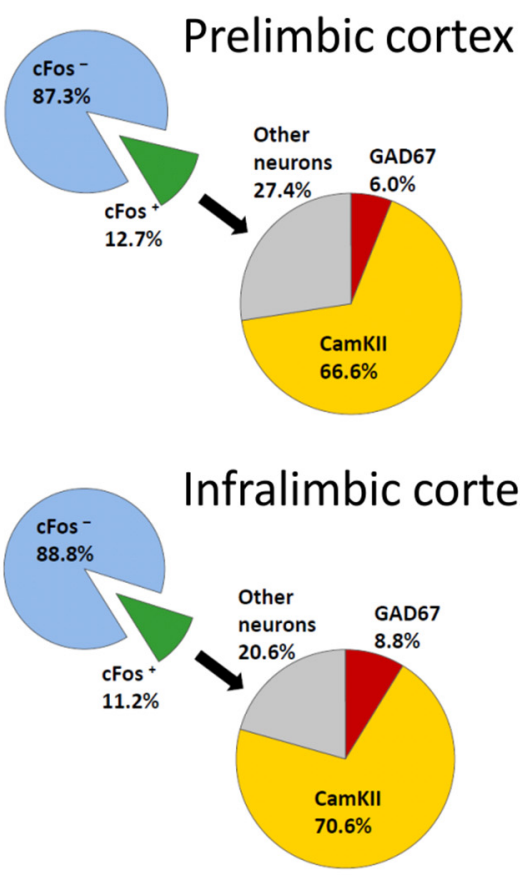

Figure 6. Characterization of cue-responsive neurons in the prelimbic and infralimbic cortex of cFos-lacZ rats after cue-induced reinstatement of alcohol seeking. $A$, Representative images of cFos and NeuN (top row), cFos and GAD67 (middle row), cFos and CaMKII (bottom row) double-labeling are shown. Scale bar, $50 \mu \mathrm{m}$. Arrows indicate colocalization. B, Quantification of double-labelings of the PL neurons, $12.7 \%$ were cFos-positive; $6 \%$ of the cFos-positive neurons were GAD 67-positive, and 66.6\% of all cFos-positive neurons were CaMKII-positive; $11.2 \%$ of all IL neurons were cFos-positive; $8.8 \%$ of the cFos-positive neurons were GAD67-positive, and 70.6\% of the cFos-positive neurons were CaMKII-positive.

type-specific markers (NeuN, GAD67 or CamKinaseII as panneuronal, GABAergic and glutamatergic markers, respectively; Fig. 6A). Quantification of colocalization demonstrated that both in the IL and PL regions somewhat $>10 \%$ of all neurons are cFos-positive, and more than two-thirds of those belong to the glutamatergic class (Fig. 6B). In line with similar studies (Bossert et al., 2011; Cruz et al., 2014b), cue responsive neuronal ensembles are formed by a small but substantial number of neurons in a given brain region.

Selective inactivation of prelimbic neuronal ensembles has no effect on alcohol seeking

Given the similar cFos response of IL and PL, and that a functional distinction in behavioral control, including cocaine seeking, is established for these regions (Heidbreder and Groenewegen, 2003; Peters et al., 2009), we next studied the potential role of PL neuronal ensembles in the control of alcohol seeking. A separate cohort of cFos-lacZ rats was trained to selfadminister alcohol and equipped with guide cannulae as described above. The prospective Daun02 and control groups showed no differences in alcohol self-administration ( $n=7$ vs 8 , $F_{(1,13)}=0.16$, n.s.) and cue-induced reinstatement after extinction (two-way repeated-measures ANOVA: main effect of the sessions, $F_{(1,13)}=79.14, p<0.001$; treatment, $F_{(1,13)}=0.09$, n.s; and interaction, $F_{(1,13)}=0.2$, n.s.; post hoc test $p<0.001$ extinction vs reinstatement for both groups; Figs. $4 E, 5 E)$. Daun02 treatment did not alter reinstatement behavior on the second test (two-way repeated-measures ANOVA: main effect of treatment, $F_{(1,13)}=0.63$, n.s.; session, $F_{(1,13)}=1.89$, n.s. $)$. There was a significant interaction effect $\left(F_{(1,13)}=8.99, p<0.05\right)$ due to a drop in responding of the control (post hoc test RE1 vs RE2, $p<0.05$ ), but not in the Daun02 group. To further exclude potential un- specific treatment effects, a group of wild-type littermates $(n=8)$ of cFos-lacZ rats, which do not express $\beta$-gal, were assessed in the reinstatement procedure as described before. As expected, neither vehicle injection into the IL after RE1 nor Daun02 after RE2 resulted in a significant change in lever pressing (baseline and extinction responding: $118.3 \pm 15.6$ and $7.8 \pm 1.2$, respectively, one-way repeated-measures ANOVA; $F_{(2,14)}=0.41$, n.s.; Figs. $4 F$, $5 F)$. In the absence of indication for unspecific drug effects, we interpret the overall outcome of the PL experiment as a lack of treatment effect. In conclusion, PL neurons are involved in processing the alcohol cue as indicated by their cFos response (see below), but they do not seem to have a role in controlling behavioral output under the present condition. This result sets alcohol apart from other drugs like cocaine or heroin that show a different involvement IL and PL in the seeking response (Fuchs et al., 2005; Peters et al., 2009; Bossert et al., 2011; Willcocks and McNally, 2013).

\section{Discussion}

The mPFC is critically involved in reward learning through topdown executive control over behavior that is exerted upon evaluation of specific reward associated memories together with actual sensory and interoceptive inputs about availability of the reward and the prospect to pursue it. This function is commonly impaired in drug abuse contributing to loss of control over drug taking (Goldstein and Volkow, 2011), a defining characteristic of addiction. Our findings yield three important insights in the representation of alcohol memories in the $\mathrm{MPFC}$ and the exertion of executive control over alcohol-seeking behavior. First, within the IL a functional ensemble exists that is characterized by a common cFos response upon recall of an alcohol memory. This ensemble comprises somewhat $>10 \%$ of IL neurons of which $\sim 70 \%$ are 
principal glutamatergic neurons and somewhat $<10 \%$ interneurons. Specific ablation of this ensemble in cFos-lacZ transgenic rats by Daun02 results in excessive alcohol seeking. These data provide strong evidence that the function of this ensemble is to exert inhibitory control over the seeking response. However, this region does not seem to convey a general inhibitory tone on alcohol seeking because global silencing of the IL either permanently by Daun02 in pCAG-lacZ rats or reversibly by pharmacologically blocking GABA receptors (Willcocks and McNally, 2013 ) is without behavioral consequence. Although several studies found effects on seeking responses for other drugs of abuse by manipulating IL activity (Peters et al., 2008a; Bossert et al., 2011; LaLumiere et al., 2012), there is no support for a general inhibitory or stimulatory role of this region in drug seeking. Observed effects highly depend on the drug, specific stimuli or settings and timing, thereby supporting the idea that within this region specific ensembles are formed to subserve specific functions under specific conditions. Here, compounded cues were used for reinstatement of alcohol seeking (Ciccocioppo et al., 2002, 2003), whereby the odor is acting as a discriminative cue as part of the environment predicting alcohol availability. In this respect our procedure is similar to the context-induced reinstatement task used by (Bossert et al., 2011) for heroin-seeking experiments, but distinct from the recall of highly discrete cues used in the cocaineseeking experiments by LaLumiere et al. (2012). In view of these experimental differences, it is difficult to generalize our findings with respect to drug-specific effects. Importantly, the functional ensemble investigated here represents a snapshot defined by cFos induction upon presentation of alcohol specific cues, and thus represents only one form of ongoing coherent activity. Consequently, various ensembles are proposed to exist in parallel and to interact thereby offsetting or facilitating each other's activity (Schwindel and McNaughton, 2011; Suto et al., 2013; Cruz et al., 2014a). Importantly, control over the specific behavioral response, i.e., lever pressing upon exposure to the distinct set of cues, cannot be reestablished by repeated presentation of the alcohol cues as demonstrated by additional reinstatement tests over the course of 2 weeks. This could suggest that the link to the specific alcohol memory is permanently severed in the IL. In this case, control over newly learned associations predicting alcohol availability should still be possible. However, although linking the cFos ensemble to the alcohol memory seems plausible, other processes may be involved. The IL is considered to play a role in extinction learning (Peters et al., 2009; LaLumiere et al., 2010), which is also known to induce a cFos response (Stafford et al., 2012). The question whether and to what extend a putative "extinction ensemble" overlaps with an "alcohol memory ensemble" cannot be resolved using the present experimental approach and will require the development of in vivo methods for monitoring cFos activity.

Second, we provide evidence that the neuronal ensemble formed by cFos-responsive IL neurons is not necessary for expressing a seeking response toward alcohol per se. The reinstatement paradigm is considered as a model of relapse into addictive behaviors including compulsive alcohol drinking because the response can be elicited by a variety of stimuli, including the drug itself, drug-specific cues, or stress, all known to be important precipitators of relapse in addicted patients (Epstein et al., 2006; Martin-Fardon and Weiss, 2013; Marchant et al., 2014). Like alcohol-associated cues, also stress and alcohol itself are potent inducers of cFos expression in the mPFC and many other brain regions (Morrow et al., 2000; Zhao et al., 2006; Funk et al., 2008; Hansson et al., 2008). Here, we observed that foot shock stress elicits a seeking response independently of the presence of the functional ensemble previously involved in the cue-induced reinstatement test. This result suggests that the stress-responsive subset of neurons within the IL is different from the one activated by the presentation of the alcohol cue, although both are acting on the same behavioral output, i.e., reinstatement of lever pressing, which therefore may originate someplace else. Whether a putative functional ensemble in the IL formed in response to stress provides inhibitory or stimulatory control for shaping the behavioral output remains to be studied.

Third, PL neurons are involved in cue-induced reinstatement of alcohol seeking, but the cFos-positive subset of neurons does not impact on the behavioral output as demonstrated by similar cFos responses in IL and PL, but unaltered reinstatement responses by Daun02 lesion of the latter. This goes in line with existing concepts on functional compartmentation of mPFC subregions whereby the dorsomedial part is mainly involved in the learning of rules, whereas the IL supports flexibility in this response and shifting toward new strategies when contingencies are changing (Heidbreder and Groenewegen, 2003; Seamans et al., 2008). Our findings provide further evidence that the underlying neuronal mechanisms for various classes of drugs are different and rely on different mPFC subregions. Thus, inhibition of ventromedial PFC, which includes the IL, showed reduced responding for heroin, but no effects for cocaine and alcohol under reinstatement conditions (Fuchs et al., 2005; Willcocks and McNally, 2013). For the dorsomedial PFC including PL, reduced responding for cocaine and alcohol but no effect on heroin seeking was found. Activity-dependent silencing was only reported for heroin seeking and showed essentially no difference from global inactivation, i.e., reduced responses in IL and no effect in PL (Bossert et al., 2011). These results contrast with our findings demonstrating inhibitory control over alcohol seeking by IL circuits. Furthermore, a prominent hypothesis posits dichotomous control by IL and PL over behavior via parallel circuits involving nucleus accumbens core and shell regions, respectively, thus either inhibiting or facilitating cocaine seeking and fear responses after extinction (Peters et al., 2008a,b, 2009). Such a stringent dual model of behavioral control may apply for the processing of highly discrete signals (e.g., a distinct tone or light cue associated with an immediate, highly salient event, such as cocaine onset or punishment). Yet, it is unlikely that this model is valid for complex conditions, such as compounded cues (e.g., contextual cues or settings), or the slow onset of the pharmacological actions and interoceptive states of alcohol.

Alcohol may be particularly damaging to neurons in the IL. Repeated periods of alcohol exposure and withdrawal result in structural remodeling of mPFC neurons, such as increased spine density, altered functional connectivity, and impaired cognitive abilities in humans and in rodents (Duka et al., 2003, 2011; Holmes et al., 2012; Kroener et al., 2012). We recently found that rats with a history of alcohol dependence (Meinhardt and Sommer, 2015) display disrupted infralimbic function resulting from the inability to properly regulate glutamate release due to a loss of mGluR2 receptors (Meinhardt et al., 2013). In this model, we also found decreased basal expression of cFos and other immediate early genes in the IL, as well as reduced dopamine levels in this region (Hansson et al., 2008; Meinhardt et al., 2013, 2015). The interaction of glutamatergic and dopaminergic inputs is an important trigger for inducing neuronal cFos expression (Cruz et al., 2014a). This response seems to be necessary for adequately controlling alcohol seeking, but is likely to be disturbed in alcohol-dependent rats. Interestingly, even much lower doses of 
alcohol lead to altered cFos expression and connectivity of the IL associated with impaired cognitive flexibility long after the acute effects of alcohol have subsided (George et al., 2012). Thus, progressive loss of inhibitory control from IL neurons might be a switch into alcohol addiction.

In conclusion, the present study provides new insights in the infralimbic control over alcohol-seeking behavior, inasmuch as alcohol seeking involves the formation of highly specific neuronal ensembles with functional and regional characteristics that are distinct from other drugs of abuse. By introducing a new tool, the pCAG-lacZ transgenic rat line, we expand the versatility of the Daun02 method allowing comparison of activity-dependent versus nonselective inactivation using the same molecular mechanism, and established that the silencing is due to apoptosis. Consequently, the functional ensembles targeted by this approach are likely to be permanently inactivated. In future studies, such ensembles need to be studied in vivo to gain understanding how ensembles are formed and interact under various conditions related to alcohol behaviors and addiction.

\section{References}

Bossert JM, Stern AL, Theberge FR, Cifani C, Koya E, Hope BT, Shaham Y (2011) Ventral medial prefrontal cortex neuronal ensembles mediate context-induced relapse to heroin. Nat Neurosci 14:420-422. CrossRef Medline

Buzsaki G (2010) Neural syntax: cell assemblies, synapsembles, and readers. Neuron 68:362-385. CrossRef Medline

Cannella N, Economidou D, Kallupi M, Stopponi S, Heilig M, Massi M, Ciccocioppo R (2009) Persistent increase of alcohol-seeking evoked by neuropeptide $\mathrm{S}$ : an effect mediated by the hypothalamic hypocretin system. Neuropsychopharmacology 34:2125-2134. CrossRef Medline

Ciccocioppo R, Martin-Fardon R, Weiss F (2002) Effect of selective blockade of $\mathrm{mu}(1)$ or delta opioid receptors on reinstatement of alcohol-seeking behavior by drug-associated stimuli in rats. Neuropsychopharmacology 27:391-399. CrossRef Medline

Ciccocioppo R, Lin D, Martin-Fardon R, Weiss F (2003) Reinstatement of ethanol-seeking behavior by drug cues following single versus multiple ethanol intoxication in the rat: effects of naltrexone. Psychopharmacology 168:208-215. CrossRef Medline

Ciccocioppo R, Economidou D, Cippitelli A, Cucculelli M, Ubaldi M, Soverchia L, Lourdusamy A, Massi M (2006) Genetically selected Marchigian Sardinian alcohol-preferring (msP) rats: an animal model to study the neurobiology of alcoholism. Addict Biol 11:339-355. CrossRef Medline

Crombag HS, Shaham Y (2002) Renewal of drug seeking by contextual cues after prolonged extinction in rats. Behav Neurosci 116:169-173. CrossRef Medline

Cruz FC, Koya E, Guez-Barber DH, Bossert JM, Lupica CR, Shaham Y, Hope BT (2013) New technologies for examining the role of neuronal ensembles in drug addiction and fear. Nat Rev Neurosci 14:743-754. CrossRef Medline

Cruz FC, Javier Rubio F, Hope BT (2014a) Using c-fos to study neuronal ensembles in corticostriatal circuitry of addiction. Brain Res. Advance online publication. Retrieved November 11, 2014. doi:10.1016/ j.brainres.2014.11.005. CrossRef Medline

Cruz FC, Babin KR, Leao RM, Goldart EM, Bossert JM, Shaham Y, Hope BT (2014b) Role of nucleus accumbens shell neuronal ensembles in contextinduced reinstatement of cocaine-seeking. J Neurosci 34:7437-7446. CrossRef Medline

Dayas CV, Liu X, Simms JA, Weiss F (2007) Distinct patterns of neural activation associated with ethanol seeking: effects of naltrexone. Biol Psychiatry 61:979-989. CrossRef Medline

Duka T, Townshend JM, Collier K, Stephens DN (2003) Impairment in cognitive functions after multiple detoxifications in alcoholic inpatients. Alcohol Clin Exp Res 27:1563-1572. CrossRef Medline

Duka T, Trick L, Nikolaou K, Gray MA, Kempton MJ, Williams H, Williams SC, Critchley HD, Stephens DN (2011) Unique brain areas associated with abstinence control are damaged in multiply detoxified alcoholics. Biol Psychiatry 70:545-552. CrossRef Medline

Engeln M, Bastide MF, Toulme E, Dehay B, Bourdenx M, Doudnikoff E, Li Q,
Gross CE, Boue-Grabot E, Pisani A, Bezard E, Fernagut PO (2014) Selective inactivation of striatal $\mathrm{FosB} / \delta \mathrm{FosB}$-expressing neurons alleviates L-dopa-induced dyskinesia. Biol Psychiatry. Advance online publication. Retrieved July 15, 2014. doi:10.1016/j.biopsych.2014.07.007. CrossRef Medline

Epstein DH, Preston KL, Stewart J, Shaham Y (2006) Toward a model of drug relapse: an assessment of the validity of the reinstatement procedure. Psychopharmacology 189:1-16. CrossRef Medline

Farquhar D, Pan BF, Sakurai M, Ghosh A, Mullen CA, Nelson JA (2002) Suicide gene therapy using E. coli beta-galactosidase. Cancer Chemother Pharmacol 50:65-70. CrossRef Medline

Fuchs RA, Evans KA, Ledford CC, Parker MP, Case JM, Mehta RH, See RE (2005) The role of the dorsomedial prefrontal cortex, basolateral amygdala, and dorsal hippocampus in contextual reinstatement of cocaine seeking in rats. Neuropsychopharmacology 30:296-309. CrossRef Medline

Funk D, Li Z, Coen K, Lê AD (2008) Effects of pharmacological stressors on c-fos and CRF mRNA in mouse brain: relationship to alcohol seeking. Neurosci Lett 444:254-258. CrossRef Medline

George O, Sanders C, Freiling J, Grigoryan E, Vu S, Allen CD, Crawford E, Mandyam CD, Koob GF (2012) Recruitment of medial prefrontal cortex neurons during alcohol withdrawal predicts cognitive impairment and excessive alcohol drinking. Proc Natl Acad Sci U S A 109:1815618161. CrossRef Medline

Goldstein RZ, Volkow ND (2011) Dysfunction of the prefrontal cortex in addiction: neuroimaging findings and clinical implications. Nat Rev Neurosci 12:652-669. CrossRef Medline

Hansson AC, Rimondini R, Neznanova O, Sommer WH, Heilig M (2008) Neuroplasticity in brain reward circuitry following a history of ethanol dependence. Eur J Neurosci 27:1912-1922. CrossRef Medline

Hara H, Friedlander RM, Gagliardini V, Ayata C, Fink K, Huang Z, ShimizuSasamata M, Yuan J, Moskowitz MA (1997) Inhibition of interleukin 1beta converting enzyme family proteases reduces ischemic and excitotoxic neuronal damage. Proc Natl Acad Sci U S A 94:2007-2012. CrossRef Medline

Hebb DO (1949) The organization of behavior: a neuropsychological theory. New York: Wiley.

Heidbreder CA, Groenewegen HJ (2003) The medial prefrontal cortex in the rat: evidence for a dorso-ventral distinction based upon functional and anatomical characteristics. Neurosci Biobehav Rev 27:555-579. CrossRef Medline

Holmes A, Fitzgerald PJ, MacPherson KP, DeBrouse L, Colacicco G, Flynn SM, Masneuf S, Pleil KE, Li C, Marcinkiewcz CA, Kash TL, Gunduz-Cinar O, Camp M (2012) Chronic alcohol remodels prefrontal neurons and disrupts NMDAR-mediated fear extinction encoding. Nat Neurosci 15: 1359-1361. CrossRef Medline

Jantas D, Lason W (2009) Protective effect of memantine against doxorubicin toxicity in primary neuronal cell cultures: influence a development stage. Neurotox Res 15:24-37. CrossRef Medline

Kasof GM, Mandelzys A, Maika SD, Hammer RE, Curran T, Morgan JI (1995) Kainic acid-induced neuronal death is associated with DNA damage and a unique immediate-early gene response in c-fos-lacZ transgenic rats. J Neurosci 15:4238-4249. Medline

Koya E, Golden SA, Harvey BK, Guez-Barber DH, Berkow A, Simmons DE, Bossert JM, Nair SG, Uejima JL, Marin MT, Mitchell TB, Farquhar D, Ghosh SC, Mattson BJ, Hope BT (2009) Targeted disruption of cocaineactivated nucleus accumbens neurons prevents context-specific sensitization. Nat Neurosci 12:1069-1073. CrossRef Medline

Kroener S, Mulholland PJ, New NN, Gass JT, Becker HC, Chandler LJ (2012) Chronic alcohol exposure alters behavioral and synaptic plasticity of the rodent prefrontal cortex. PloS One 7:e37541. CrossRef Medline

LaLumiere RT, Niehoff KE, Kalivas PW (2010) The infralimbic cortex regulates the consolidation of extinction after cocaine self-administration. Learn Mem 17:168-175. CrossRef Medline

LaLumiere RT, Smith KC, Kalivas PW (2012) Neural circuit competition in cocaine-seeking: roles of the infralimbic cortex and nucleus accumbens shell. Eur J Neurosci 35:614-622. CrossRef Medline

Liu X, Weiss F (2002) Additive effect of stress and drug cues on reinstatement of ethanol seeking: exacerbation by history of dependence and role of concurrent activation of corticotropin-releasing factor and opioid mechanisms. J Neurosci 22:7856-7861. Medline

Marchant NJ, Kaganovsky K, Shaham Y, Bossert JM (2014) Role of cortico- 
striatal circuits in context-induced reinstatement of drug seeking. Brain Res. Advance online publication. Retrieved September 6, 2014. doi: 10.1016/j.brainres.2014.09.004. CrossRef Medline

Martin-Fardon R, Weiss F (2013) Modeling relapse in animals. Curr Top Behav Neurosci 13:403-432. CrossRef Medline

Meinhardt MW, Sommer WH (2015) Postdependent state in rats as a model for medication development in alcoholism. Addict Biol 20:1-21. CrossRef Medline

Meinhardt MW, Hansson AC, Perreau-Lenz S, Bauder-Wenz C, Stählin O, Heilig M, Harper C, Drescher KU, Spanagel R, Sommer WH (2013) Rescue of infralimbic mGluR2 deficit restores control over drug-seeking behavior in alcohol dependence. J Neurosci 33:2794-2806. CrossRef Medline

Meinhardt MW, Sévin DC, Klee ML, Dieter S, Sauer U, Sommer WH (2015) The neurometabolic fingerprint of excessive alcohol drinking. Neuropsychopharmacology 40:1259-1268. CrossRef Medline

Morgan JI, Curran T (1991) Stimulus-transcription coupling in the nervous system: involvement of the inducible proto-oncogenes fos and jun. Annu Rev Neurosci 14:421-451. CrossRef Medline

Morrow BA, Elsworth JD, Lee EJ, Roth RH (2000) Divergent effects of putative anxiolytics on stress-induced fos expression in the mesoprefrontal system of the rat. Synapse 36:143-154. CrossRef Medline

Mortensen ME, Cecalupo AJ, Lo WD, Egorin MJ, Batley R (1992) Inadvertent intrathecal injection of daunorubicin with fatal outcome. Med Pediatr Oncol 20:249-253. CrossRef Medline

Paxinos G, Watson C (1998) The rat brain in stereotaxic coordinates. San Diego: Academic, San Diego.

Peters J, LaLumiere RT, Kalivas PW (2008a) Infralimbic prefrontal cortex is responsible for inhibiting cocaine seeking in extinguished rats. J Neurosci 28:6046-6053. CrossRef Medline

Peters J, Vallone J, Laurendi K, Kalivas PW (2008b) Opposing roles for the ventral prefrontal cortex and the basolateral amygdala on the spontaneous recovery of cocaine-seeking in rats. Psychopharmacology 197:319326. CrossRef Medline

Peters J, Kalivas PW, Quirk GJ (2009) Extinction circuits for fear and addiction overlap in prefrontal cortex. Learn Mem 16:279-288. CrossRef Medline

Sanchis-Segura C, Spanagel R (2006) Behavioural assessment of drug reinforcement and addictive features in rodents: an overview. Addict Biol 11:2-38. CrossRef Medline

Santone KS, Oakes SG, Taylor SR, Powis G (1986) Anthracycline-induced inhibition of a calcium action potential in differentiated murine neuroblastoma cells. Cancer Res 46:2659-2664. Medline

Schmued LC, Hopkins KJ (2000) Fluoro-Jade B: a high affinity fluorescent marker for the localization of neuronal degeneration. Brain Res 874:123130. CrossRef Medline

Schönig K, Weber T, Frömmig A, Wendler L, Pesold B, Djandji D, Bujard H, Bartsch D (2012) Conditional gene expression systems in the transgenic rat brain. BMC Biol 10:77. CrossRef Medline

Schwindel CD, McNaughton BL (2011) Hippocampal-cortical interactions and the dynamics of memory trace reactivation. Prog Brain Res 193:163177. CrossRef Medline

Seamans JK, Lapish CC, Durstewitz D (2008) Comparing the prefrontal cortex of rats and primates: insights from electrophysiology. Neurotox Res 14:249-262. CrossRef Medline

Sheng M, Greenberg ME (1990) The regulation and function of c-fos and other immediate early genes in the nervous system. Neuron 4:477-485. CrossRef Medline

Sommer W, Bjelke B, Ganten D, Fuxe K (1993) Antisense oligonucleotide to c-fos induces ipsilateral rotational behaviour to d-amphetamine. Neuroreport 5:277-280. CrossRef Medline

Sommer W, Rimondini R, O'Connor W, Hansson AC, Ungerstedt U, Fuxe K (1996) Intrastriatally injected c-fos antisense oligonucleotide interferes with striatonigral but not striatopallidal gamma-aminobutyric acid transmission in the conscious rat. Proc Natl Acad Sci U S A 93:14134-14139. CrossRef Medline

Spanagel R, Durstewitz D, Hansson A, Heinz A, Kiefer F, Köhr G, Matthäus F, Nöthen MM, Noori HR, Obermayer K, Rietschel M, Schloss P, Scholz H, Schumann G, Smolka M, Sommer W, Vengeliene V, Walter H, Wurst W, Zimmermann US; Addiction GWAS Resource Group, Stringer S, Smits Y, Derks EM (2013) A systems medicine research approach for studying alcohol addiction.Addict Biol 18:883-896. CrossRef Medline

Stafford JM, Raybuck JD, Ryabinin AE, Lattal KM (2012) Increasing histone acetylation in the hippocampus-infralimbic network enhances fear extinction. Biol Psychiatry 72:25-33. CrossRef Medline

Suto NH, Cauvi G, Kerr T, Mayford M, Weiss F (2013) The infralimbic cortex controls promotion and supression of reward seeking via distinct neuronal ensembles. Soc Neurosci Abstr 39:777.04.

Tolliver GA, Sadeghi KG, Samson HH (1988) Ethanol preference following the sucrose-fading initiation procedure. Alcohol 5:9-13. CrossRef Medline

Wallace DJ, Kerr JN (2010) Chasing the cell assembly. Curr Opin Neurobiol 20:296-305. CrossRef Medline

Weber T, Schönig K, Tews B, Bartsch D (2011) Inducible gene manipulations in brain serotonergic neurons of transgenic rats. PloS One 6:e28283. CrossRef Medline

Wedzony K, Koros E, Czyrak A, Chocyk A, Czepiel K, Fijal K, Mackowiak M, Rogowski A, Kostowski W, Bienkowski P (2003) Different pattern of brain c-Fos expression following re-exposure to ethanol or sucrose selfadministration environment. Naunyn Schmiedebergs Arch Pharmacol 368:331-341. CrossRef Medline

Whiteford HA, Degenhardt L, Rehm J, Baxter AJ, Ferrari AJ, Erskine HE, Charlson FJ, Norman RE, Flaxman AD, Johns N, Burstein R, Murray CJ, Vos T (2013) Global burden of disease attributable to mental and substance use disorders: findings from the global burden of disease study 2010. Lancet 382:1575-1586. CrossRef Medline

Willcocks AL, McNally GP (2013) The role of medial prefrontal cortex in extinction and reinstatement of alcohol-seeking in rats. Eur J Neurosci 37:259-268. CrossRef Medline

Wood JN, Grafman J (2003) Human prefrontal cortex: processing and representational perspectives. Nat Rev Neurosci 4:139-147. CrossRef Medline

Zhao Y, Dayas CV, Aujla H, Baptista MA, Martin-Fardon R, Weiss F (2006) Activation of group II metabotropic glutamate receptors attenuates both stress and cue-induced ethanol-seeking and modulates c-fos expression in the hippocampus and amygdala. J Neurosci 26:9967-9974. CrossRef Medline 